\title{
The Impact of Traumatic Experiences on Individual's Health and Conduct: A Case Study of Rwandans Cultural Identity in Finland and Belgium
}

\author{
Jean d'Amour Banyanga \\ Faculty of Education and Welfare Studies, Social Science, Developmental Psychology, \\ Åbo Akademi University, Vasa, Finland \\ E-mail: jean.banyanga@abo.fi
}

\begin{abstract}
Trauma is one of the dominant ways of demonstrating an individual's relationship with his/her past. It concerns individuals, groups, communities and nations; particularly when considering the experience that was subjected to collective violence. Studies have demonstrated that an individual's health, well-being and conduct are influenced by their history and cultural identity. This study aims to investigate the impact of traumatic experiences on the personal health and conduct of Rwandans traumatized by their experiences during the 1994 genocide and its aftermath, living in Finland and Belgium. A questionnaire was filled in by 341 Rwandans over 20 years of age (166 males, 175 females), with the purpose of investigating their life experiences and mental health interventions in the two host countries. The results show that Rwandans in Belgium were more satisfied than those living in Finland with the therapeutic interventions, cultural identities, and social support. Rwandans in Finland, on the other hand, relied more on psychopharmaca and the use of alcohol as a coping mechanism than those living in Belgium.
\end{abstract}

Keywords: Trauma, health, conduct, cultural identity, Finland \& Belgium.

\section{Introduction}

The concept of trauma has been described as the mental scar that a tragic event leaves on an individual victim or a witness - sometimes even on the perpetrators. Trauma is an uncontrolled reaction to the traumatic experience that people have gone through. The World Health Organization (2018) defines "health" as a complete physical condition with mental and social well-being and not just the absence of sickness or infirmity. It is a theory that has been utilized for years to clarify a state of well-being (Dolfaman, 1973, p. 491). However, mental health and well-being are two terms that go hand-in-hand and are often used synonymously in many cultures. For instance, in Japanese tradition, Mikao Usui in 1922 suggested that being connected and having a good connection with a community enables a sense of well-being because well-being is expressed and experienced within cultural and environmental contexts (Beeler, 2018).

Moreover, certain studies have demonstrated the connection between ethnic identity and happiness and well-being; they state that in general, people with an advanced sense of ethnic identity have a higher quality of life (Phinney, Horenczyk, Liebkind \& Vedder, 2001; Phinney, 1990). Cultural identity can also have an influence on the life cycle of society and it may affect family structure, patterns of influence among family members, relations with others, role performance and responsibilities, marriage, work, communication patterns, living, and consumption, as well as health and trauma healing strategies (Rwomire, 2001, pp. 56-57). Psychologically, many studies have also shown that ethnic identity is very important to the self-concept and psychological functioning of ethnic members (Gurin \& Eppy, 1975; Maldonado, 1975). As mentioned above, trauma and violence are understood to be phenomena that leave traces of the past in the present, and that this may require immediate treatment to ensure that they do not burden our future. That's why psychiatrists, historians, philosophers, and anthropologists have devoted themselves to studying trauma; they believe that the truth of the subject lies not in the psyche, mind or the brain, but the moral economy of contemporary societies.

Furthermore, according to the World Health Organization report (2016), trauma may lead to suicide which is a serious public health problem; and is the second cause of death among 15-29-year olds. The 
report states that about 800,000 individuals take their own lives every year which can be related to feelings of hopelessness and loneliness. According to Statistics Finland (2017), in Finland, loneliness and social isolation are said to be on the rise and highlighted as a major public concern. Youth and migrant groups are particularly vulnerable to experiences of loneliness. The report mentions that 824 people in Finland who are under the age of 25 committed suicides, which is higher than the average of other EU countries. Loneliness becomes a common part of migrants' lives. This is because in migrants, the significant predictor of loneliness comes from the social environment (Balážová, Gallová, Praško, Šlepecký, 2018).

According, to some studies, depression and traumatic incidents occurring during childhood can lie dormant for years, but still cause permanent damage to the hippocampus, which is part of the brain's limbic system dealing with memories (Lobban, 2012, p. 3; Figley et al., 1997, pp. 22-23). Therefore, trauma may continually influence mental health functions of young individuals throughout their entire life. However, recent longitudinal research that studied 1700 New Zealand adolescents on connectedness to their family, school, peer group, and community, showed amongst those adolescents who had a higher connectedness, their physiology and psyche were working very well; they felt secure and had a positive relationship (Crespo, Kielpikowski, Jose, \& Pryor, 2010). Studies on the effects of personal ethnic discrimination have shown that discrimination was related to negative psychological well- being, which can lead to distress, while the positive impact of ethnic identity for ethnic minorities leads to self-esteem, and trauma coping strategies (Banyanga, Kaj \& Karin, 2017; Lee, 2003).

\section{Friendship as a Key Factor for an Individual's Good Mental Health}

Weiss's theory of loneliness (1973) distinguished emotional loneliness (absence of personal intimate relationships) from social loneliness (lack of social connectedness in the community). Loneliness is an experience that arises when a person's network of social interactions is profoundly poor in either quality or quantity. Loneliness may cause poor mental health, and it is associated with an individual's conduct and mental health problems (Diamant \& Windholz, 1981; Young, 1982). According to the National Institute for Health and Welfare (NIHW, 2015), a remarkably large number of today's migrant people, especially males, lack close friends. Migrants who don't have close friends also experience greater health problems (anxiety) in comparison to nationals. Being without friends is also related to other phenomena such as bullying at school or at the workplace, which may result in not performing well, and also to suicide attempts. Among immigrants, loneliness is common, 23-29\% of males and 10-16\% of females report that they do not have any close friends with whom they could relate to and discuss confidential matters (NIHW, 2015).

Most traumatized people feel loneliness at times, for example when they move to other home address and change workplaces. Although loneliness is usually temporary, it can affect people's health (NIHW, 2015). Consequently, loneliness can have serious negative consequences, both mental and physical, including depression, suicidal thoughts, aggression, obesity, and cardiovascular disease (Cacioppo, Grippo, London, \& Goossens, 2015). According to studies by Holt-Lunstadet, Smit, Baker, Harris, \& Stephenson (2015), loneliness and social isolation are normally linked to the increased risk of early mortality when loneliness among young people is primarily related to different physical and mental health problems. In Finland, many Finns live with long-lasting loneliness. According to Junttila (2018), loneliness is not only about living far from others, but rarely meeting other people, but it can also mean that you are surrounded by opportunities for networking and social interactivity but have no contact. The loneliness may arise when an individual is surrounded by other people but does not come into contact with them. To some migrants, this kind of loneliness may stimulate feelings of shame, being unloved and making them hostile, violent, and even terrorists. Also, at the workplace, when a migrant person sits alone at the table when it is at lunchtime and there is no one to talk to, it may cause social pain, brain impulses as well as physical pain (Junttila \& Vauras 2018).

Everywhere, including Finland, school is an important social environment for everyone, but it can be devastating to migrants who experience loneliness, bullying or have problematic social relationships. These negative experiences can lead to migrant people disliking school, which in turn can harmfully affect the student's motivation, academic grades and well-being (Rönkä, Sunnari, Rautio, Koiranen, 
Taanila, 2017). Thus, migrants' coping strategies to loneliness may be to engage in alcohol consumption, drug abuse and this can have serious consequences in their lives (Elodie, Shrum, \& Lowrey, 2018).

\section{The Benefits of Cultural Identity among Traumatized People}

Moving to another country and culture is a major life change. Cultural identity has an important role to play in all societies. Cultural identity has been defined as a critical aspect of individuals' sense of belonging, and their understanding of the world (Verkuyten, 2006, pp. 224-225). Therefore, cultural identity for migrant individuals; and their ethnic identity is very important in influencing their wellbeing and their mental health issues. Their cultural identity may, therefore, promote well-being, feeling of positive secure, and a stable self-esteem (Edwards \& Romero, 2008; Wakefield \& Hudley, 2009).

Exposure to severe ethnic harassment is a common experience for minority ethnic groups worldwide. Thus, individuals develop coping strategies from their close network of people, such as family and their ethnic culture (Pearlin, 1993). According to Nordanger (2007) who studied cultural coping strategies in the aftermath of the Ethiopian and Eritrean war, common coping strategies among Tigrayans were cultural identities which were meditation and distraction. He also learned that Tigrayans' beliefs of grieving and crying have negative impacts on their health, their household, and on their relationship with God. In addition, some researchers have classified trauma coping strategies into different types according to their intended functions such as optimism (Scheier \& Carver, 1992), psychological mastery or control (Bandura, 2006), self-esteem (DuBois \& Flay, 2004), and social support (Maercker, Schutzwohl, \& Zahava, 1999, p. 215). These then become essential psychological resources that help in one's ability to manage trauma and in turn predict better mental health outcomes. Furthermore, they have pointed out that ethnic identification (Phinney, 1992; Phinney \& Ong, 2007) and acculturation (Suinn, 2010) status may be essential factors predicting mental health outcomes among migrants.

\section{Impact of Stigma on the Life of a Traumatized Person - Female Rape Victims and Children Born Out of Rape}

People's identities could be categorized into two different groups: "personal individual identity and group identity". According to studies, an estimated 250.000 to 500.000 Rwandan women were raped (Amnesty International, 2004; Des Forges 1999, p. 215; Haffajee, 2006, p. 201). Despite their effort to be accepted, women who have been raped and children born out of rapes, community rejection is a persuasive feature of their social life. Children born out of rape usually experience a significant stigma due to their origins. Of course, a lot of rejection results from distinctive preferences, the liking to their rapist fathers and the health situation to their mothers. Raped Tutsi women are often abandoned by their community and accused of collaborating with the enemy (Mukangendo 2007, p. 42). Though the process of stigmatization, certain individuals are systematically excluded from particular sorts of social benefits because they possess a particular characteristic or a member of the enemy group (Weitz, 1990; Steele \& Aromson, 1995). Rwandan children of rape face severe stigma within their communities and schools.

Stigma arises during a social interaction when an individual's actual social identity does not meet the community's normative expectations (Kurzban \& Leary, 2001). Elliott, Ziegler, Altman \& Scott (1982) suggested that stigma is a form of deviance that leads others to judge an individual as illegitimate for participation in an interaction. The stigmatization might be selective in the context that certain members of ethnic group should be systematically excluded from economic and social benefits. Thus, Rwandan Children born out of rape are stigmatized because they are negatively assessed and possess the blood of their fathers (Kurzban \& Leary, 2001). The stigmatization of children born out of rape has become an alarming characteristic of modern society, both in the developing and developed the world. As a matter of concern, studies in developmental psychobiology suggest that the consequences of trauma in childhood may produce negative effects on brain development, and may also lead him to damaging effects on behavioral development, and school performance (Van Ee, Kleber, \& Mooren, 2012). Additionally, in many circumstances, because of traumatic experiences at home, children are disposed to become street children and fall into drug abuse, begging and criminality. 


\section{$5 \quad$ Method}

\subsection{Sample}

A total of 341 respondents (166 males, 175 females), 50 from Finland and 291 from Belgium, participated in the study. The mean age of the respondents was 44.4 years $(\mathrm{SD}=11.9)$; there was no difference between males and females regarding age. The respondents had come to Belgium and Finland either as refugees or on other grounds after the 1994 genocide. At the time of the interview, they were staying in 13 different locations in Belgium and 14 locations in Finland. The participants were selected according to the following criteria: they had to be above 20 years of age, they should be native Rwandans or born as a consequence of rape during the 1994 genocide and its aftermath, they should speak the local language, Kinyarwanda, and have a residence permit.

\subsection{Instrument}

Both quantitative and qualitative data was collected. The quantitative data was collected using a paperand-pencil questionnaire. It included several parts related to experiences and coping with traumatization due to the 1994 genocide and its aftermath. In the present study, items regarding methods of coping with the trauma and their experiences of psychological treatment received in their new country are analyzed. The exact wordings of reported items are presented in Table 1. The response range to all items ranged from 0 (does not agree at all) to 4 (strongly agrees).

The participants were also interviewed about their experiences of the genocide and its aftermath, the possibility of experiencing love and forgiveness towards those who wounded them, the counseling they have received, and the healing mechanisms they use to cope with their trauma. The aim was to explore in detail the perceptions, feelings, and experiences of the participants and to seek meaning in events and interactions, providing a clearer understanding of how they make sense of their experiences and coping strategies they use to cope with their trauma.

\subsection{Procedure}

The questionnaires were dispatched in 27 different locations in Finland and Belgium. Narrative interviews were conducted in local languages Kinyarwanda and French. The data was collected during a 13 month period from 1.8.2015 to 30.8.2016.

\subsection{Ethical Considerations}

Due to the potential sensitivity of the questions and the vulnerability of the target group, ethical questions were considered very carefully. The study adheres to the principles concerning human research ethics of the Declaration of Helsinki (World Medical Association, 2013), as well as to the guidelines for responsible conduct of research issued by the Finnish Advisory Board on Research Integrity (2012). The respondents were informed of the purpose and procedure of the study. They were aware that their participation was voluntary and that no consequences would follow if they refused to participate in it.

\section{Results}

\subsection{Quantitative Results}

A multivariate analysis of variance (MANOVA) was conducted measuring differences between Rwandans living in Belgium and Finland on the thirteen dependent variables of the study, with age as a covariate. The results are presented in Table 1 and Figure 1. 
Table 1. Results of a Multivariate Analysis of Variance (MANOVA) Measuring Differences between Rwandan Respondents from Belgium and Finland on Thirteen Dependent Variables with Age as Covariate $(\mathrm{N}=337)$

\begin{tabular}{|c|c|c|c|c|c|}
\hline & $F$ & $d f$ & $p \leqslant$ & $\eta_{p}{ }^{2}$ & $\begin{array}{l}\text { Country with } \\
\text { Higher Mean }\end{array}$ \\
\hline Effect of Age as Covariate, Multivariate Analysis & 6.42 & 13,322 & .001 & .206 & \\
\hline \multicolumn{6}{|l|}{ Effect of Country of Residence (Belgium vs. Finland) } \\
\hline Multivariate Analysis & 7.29 & 13,322 & .001 & .227 & \\
\hline \multicolumn{6}{|l|}{ Univariate Analyses } \\
\hline Received social support in host country & 9.57 & 1,334 & .002 & .028 & Belgium \\
\hline Therapy given in host country perceived as valuable & 4.72 & " & .030 & .014 & Belgium \\
\hline Personal benefit of therapy received in host country & 1.96 & " & $N s$ & .006 & \\
\hline Received support from friends to cope with trauma & 5.24 & " & .023 & .015 & Belgium \\
\hline Received support from family to cope with trauma & 0.27 & " & $N s$ & .001 & \\
\hline Received support from pastor/priest to cope with trauma & 3.89 & " & .049 & .012 & Belgium \\
\hline Received support from spiritual healers to cope with trauma & 0.06 & " & $N s$ & .000 & \\
\hline Used traditional means to cope with trauma & 0.13 & " & $N s$ & .000 & \\
\hline Used Christian prayers to cope with trauma & 0.77 & " & $N s$ & .002 & \\
\hline Used psychopharmaca to cope with trauma & 21.54 & " & .001 & .061 & Finland \\
\hline Joined trauma survivors' group to cope with trauma & 19.17 & $"$ & .001 & .054 & Belgium \\
\hline Benefitted from trauma survivors' group attendance & 17.01 & " & .001 & .048 & Belgium \\
\hline Used alcohol to cope with trauma & 13.31 & " & .001 & .038 & Finland \\
\hline
\end{tabular}

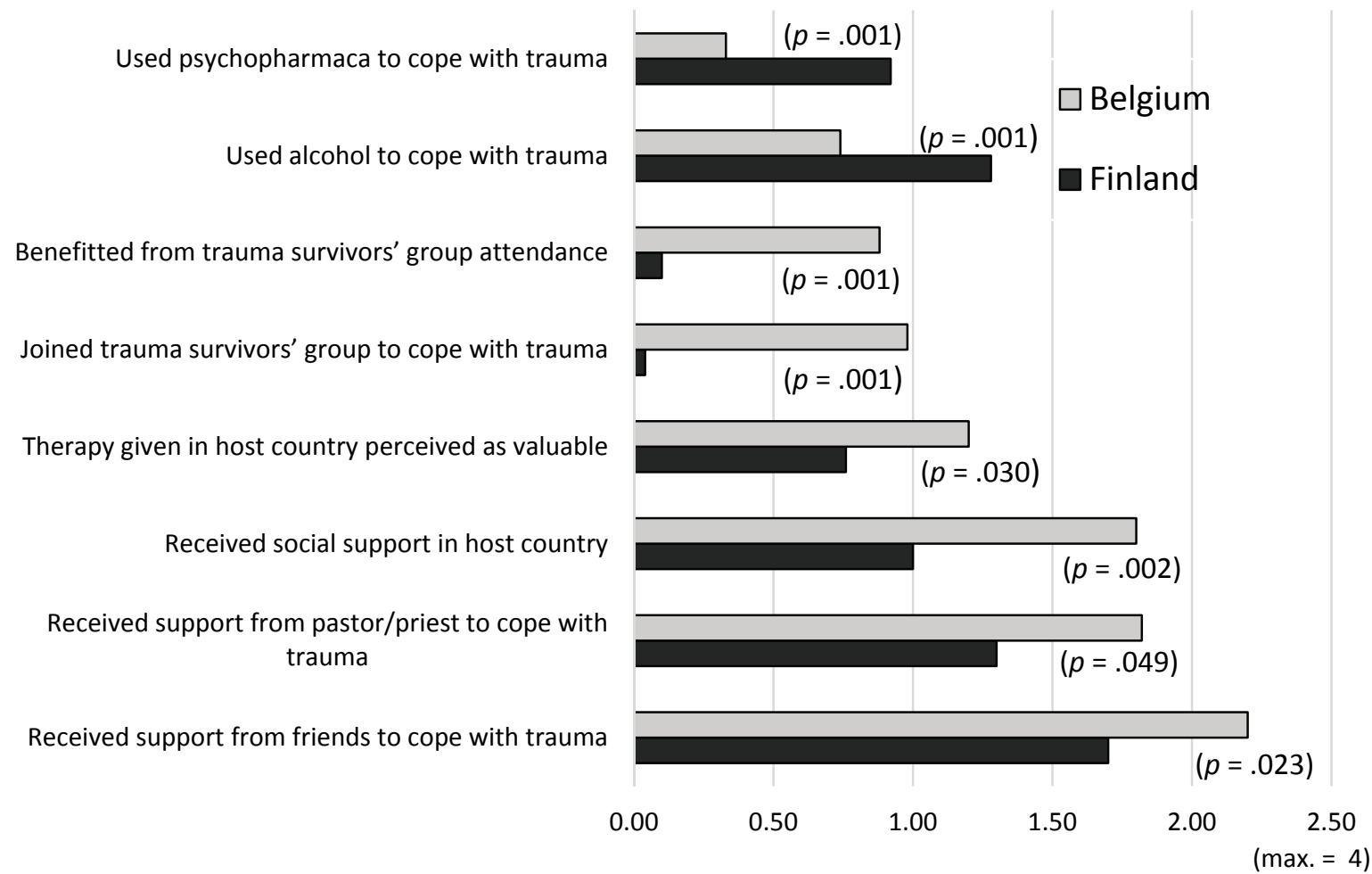

Figure 1. Differences in mean values on eight dependent variables for respondents living in Belgium and Finland $(\mathrm{N}=337)$.

As shown in Table 1, there were significant differences between respondents from Belgium and Finland on eight of the thirteen variables. Those living in Belgium scored higher on "received social support in host country", "therapy given in host country is perceived as valuable", "support received 
from friends to cope with trauma", "support received from pastor/priest to cope with trauma", "joined trauma survivors' group to cope with trauma", and "benefitted from trauma survivors' group attendance". Those living in Finland scored higher on "used psychopharmaca to cope with trauma", and "used alcohol to cope with trauma". Thus, the results suggest that Rwandans living in Belgium were more satisfied with the psychological support and interventions they had received than those living in Finland, who instead had to rely on psychopharmaca and alcohol to cope with their psychological wounds.

As Table 1 also shows, age was a significant covariate in the MANOVA. In order to find out which variables were associated with age, a correlation analysis was performed. The results are presented in Table 2. Eight of the thirteen variables correlated moderately, but significantly, with age. Seven of these were positive correlations, and only one was negative: the use of alcohol. That is, younger respondents tended to rely more on alcohol than older ones. The participation in survivors' groups had the highest correlation with age.

Table 2. Results of a MANOVA Comparing female rape victims during the genocide and its aftermath with women who had not been raped, on eight dependent variables $(\mathrm{N}=174)$, cf. Fig. 1.

\begin{tabular}{|c|c|c|c|c|}
\hline & $F$ & $d f$ & $p$ & $\eta_{p}^{2}$ \\
\hline Multivariate analysis & 6.12 & 8,165 & .001 & .229 \\
\hline \multicolumn{5}{|l|}{ Univariate analyses } \\
\hline Do you use alcohol to cope with your trauma? & 8.71 & 1,172 & .004 & .048 \\
\hline Do you use medicines to cope with your trauma? & 20.75 & " & .001 & .108 \\
\hline Is it possible for you to love and forgive those who wounded you in your life? & 3.81 & " & .053 & .022 \\
\hline Do you live peacefully with other Rwandans? & 23.83 & " & .001 & .122 \\
\hline Do you have sleeping problems? & 5.07 & $"$ & .026 & .029 \\
\hline Do you have bad dreams? & 8.14 & $"$ & .005 & .045 \\
\hline Do you feel hatred and anger against the people who brought trauma into your life? & 4.20 & " & .042 & .024 \\
\hline Do you have fear? & 10.61 & $"$ & .001 & .058 \\
\hline
\end{tabular}

Do you use alcohol to cope with your trauma?

Do you use medicines to cope with your trauma?

Is it possible for you to love and forgive those who wounded you in your life?

Do you live peacefully with other Rwandans?

Do you still have sleeping problems?

Do you still have bad dreams?

Do you still feel hatred and anger against the people who brought trauma into your life?

Do you still have fear?

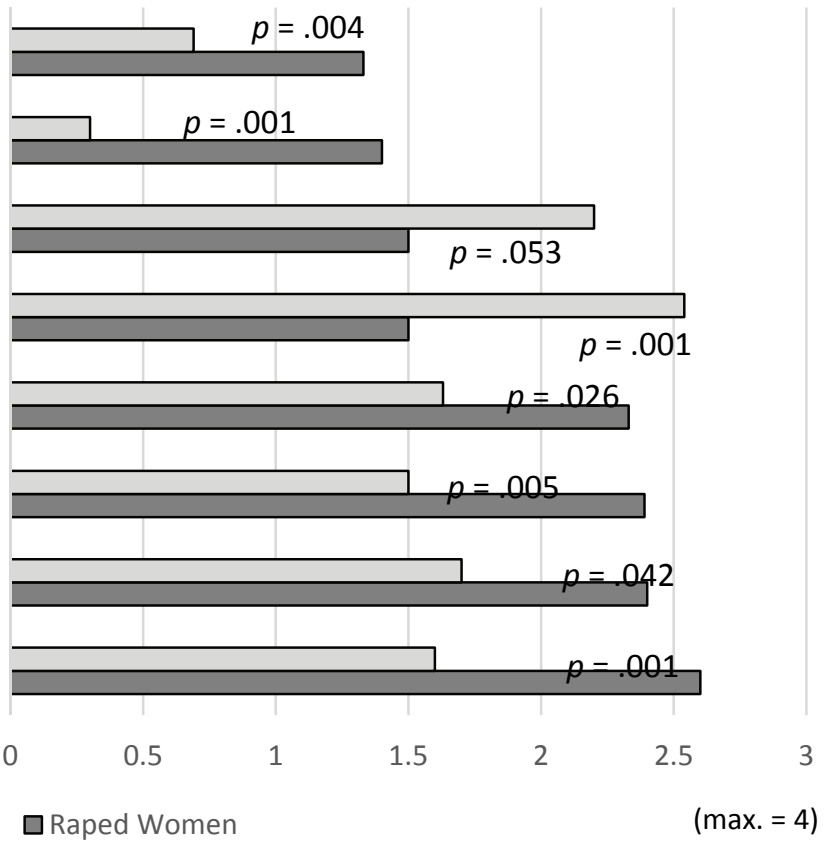

Figure 2. Mean values on eight dependent variables measuring concomitants of rape during the Rwandan genocide and its aftermath $(\mathrm{N}=174)$, c.f. Table 2 . 


\subsection{Qualitative Results}

Trauma may cause persistent fatigue, sleeping disorders, nightmares, fear, anxiety, and flashbacks. Practically few Rwandans were able to receive counseling from Finnish and Belgian psychologists, and also, few were able to receive governmental social benefits. However, there are still a substantial number of Rwandans who have not benefited from the counseling they received. In their verbal stories, they claim that Belgian and Finnish psychologists do not understand the genocide and their personal experiences. Consequently, among the Rwandans in Finland and Belgium, there are quite a number of individuals who rely on their cultural identities such as church-going, reading of the Bible, and testimonies to cope with their traumatic experiences. Many of the respondents argue that Belgian and Finnish authorities should talk to asylum seekers more, to get to know about their experiences. They feel that they need to be listened to.

Emotional reactions to trauma may be influenced by an individual's sociocultural history. Most Rwandans in Belgium and Finland have suffered in some way from the 1994 genocide and lost one or several members of their families: siblings, parents, wives, husbands, children, as well as neighbors, friends, and property. Some have family members still scattered throughout the refugee camps in African countries, while others have family members in prison. Some respondents had been imprisoned for many years in Rwanda without any formal charge against them, and they did not receive any compensation. Trauma may influence an individual's sociocultural factors and emotions. Therefore, the young Rwandans feel that they do not know much about their country and that they have lost their cultural identity. Finally, the study shows that cultural identity and religion have played an important role in behavioral changes, trauma healing and reconciliation among Rwandan church-goers in Finland and Belgium.

\section{Discussion}

The study shows that some traumatized Rwandans in Finland and Belgium use somatization as a means to calm down their emotional pain. They may have specific conditions that require medical attention in terms of psychological interventions. However, some Rwandans use self-harm (smoking cigarettes, drinking alcohol) to cope with emotional or physical distress and others rely on psychopharmaca to get help for their mental pain. It appears that Rwandans in Finland suffered more from their trauma, due to loneliness and the language barrier. The Rwandan group in Finland is a quite a small community, while Belgium has a huge Rwandan community, the largest in the western countries. In 2012, the number of Rwandans living in Belgian territory was between 30,000 and 40,000 (Schildt, 2013, p. 17). According to Statistics Finland (1990-2018), by 2018, Finland hosted 513 (258 males \& 255 females) Rwandans who had come as refugees, students, and on other grounds.

According to Samovar, Porter, McDaniel, and Roy, how people think and how they speak are determined to a large extent by their cultural identity (Samovar, Porter, McDaniel, \& Roy, 2012, pp. 143-151). In Belgium, there is a big Rwandan community with many restaurants, bars, and associations, where Rwandans can meet and discuss their issues. As a French-speaking country, it is easier for many Rwandans to integrate into Belgium's system and culture, while in Finland; it takes three years of learning the country's language and culture. This might be the main reason why there are many traumatized Rwandans in Finland in comparison to Belgium. There could be more efforts from both Belgian and Finish authorities to fight against racism and show a warm welcome towards immigrants because people who are traumatized feel even worse if they face racism.

\section{References}

1. Amnesty International (2004). Rwanda: "Marked for death", rape survivors living with HIV/AIDS. Retrieved from: http://www.refworld.org/docid/4129fd524.html

2. Balážová, M., Gallová, I., Praško, J., Šlepecký, M, (2018). Family environment as predictor of adolescents' loneliness. Grant Journal. https://www.researchgate.net/publication/316102565_Family_environment_as_ predictor_of_adolescents'_loneliness 
3. Bandura, A. C. (2006). Toward a psychology of human agency. Perspectives on Psychological science, 1, 164180.

4. Banyanga, J. A., Björkqvist, K., \& Österman, K. (2017). The trauma of women who were raped and children who were born as a result of rape during the Rwandan genocide: Cases from the Rwandan diaspora. Pyrex Journal of African Studies and Development, 3, 31-39.

5. Beeler, D. (2008). A Reiki sense of well-being. Anthropology News. https://doi.org/10.1111/AN.747

6. Cacioppo, S., Grippo, A.J., London, S., Goossens, L., \& Cacioppo, J. T (2015). Loneliness clinical import and interventions. Perspectives on Psychological Science, 10, 238-249.

7. Crespo, C. Kielpikowski, M., Jose, P. M., \& Pryor, J. (2010). Relationships between family connectedness and body satisfaction: A longitudinal study of adolescent girls and boys. Journal of Youth and Adolescence, 39, $1392-1401$.

8. Des Forges, A. L. (1999). Leave none to tell the story: Genocide in Rwanda. New York: Human Rights Watch.

9. Diamant, L.; and Windholz,G. (1981). Loneliness in college students: Some therapeutic considerations. Journal of College Student Personnel, 22, 515-522.

10. Dolfman, M. L. (1973). The concept of health: an historic and analytic examination. Journal of school Health, 43, 491-497.

11. DuBois, D. L., Flay, B. R. (2004). The healthy pursuit of self-esteem: Comment on an alternative to the Crocker and Park. Formulation Psychological Bulletin, 13, 415-420.

12. Edwards, L \& Romero, A. J. (2008). Coping with discrimination among Mexican descent adolescents. Hispanic Journal of Behavioral Sciences, 30, 24-39.

13. Elliot, G. C., Ziegler, H. L, Altman, B. M., \& Scott, D. R. (1982). Understanding stigma: Dimensions of Deviance Coping. Deviant Behavior, 3, 275-300.

14. Elodie, G., Shrum, L. J., Lowrey, T. M (2018). Coping with loneliness through materialism: Strategies matter for adolescent development of Unethical behaviours. Journal of Business Ethics, 152, 103-122.

15. Figley, C. R., Bride, B. E., \& Mazza, N. (1997). Death and trauma: The traumatology of grieving. Washington, DC: Taylor \& Francis.

16. Finnish Advisory Board on Research Integrity (2012). Guidelines for responsible conduct of research and procedures for handling allegations of misconduct in Finland. http://www.tenk.fi/sites/tenk.fi/files/ HTK_ohje_2012.pdf

17. Gurin, P., \& Epps, E. (1975). Black consciousness, identity, and achievement. New York: Wiley.

18. Haffajee, R. L. (2006). Prosecuting crimes of rape and sexual violence at the ICTR: The application of joint criminal enterprise theory. Harvard Journal of Law and Gender, 29, 201-221.

19. Holt-Lunstad, J., Smith TB, Baker, M., Harris, T., Stephenson D. (2015). Loneliness and social isolation as risk factors for mortality: a meta-analytic review. Perspect Pscychol Sci, 10, 227- 237.

20. Junttila N. \& Vauras, M. (2009). Loneliness among school-aged children and their parents. Development and Aging, 50, 211-219.

21. Junttila, N. 2018. Kaiken keskellä yksin: aikuisten yksinäisyydestä. Kustannusosakeyhtiö. Tammi.

22. Kurzban, R., \& Leary, M. R. (2001) Evolutionary origins of stigmatization: The functions of social exclusion. Psychological Bulletin, 127, 187-208.

23. Lee, R. M. (2003). Do ethnic identity and other group orientation protect against discrimination for Asian Americans? Journal of Counselling Psychology, 50, 133-141.

24. Lobban, J. (2012). The invisible wound: Veteran's art therapy. International Journal of Art Therapy, 19, 1-16.

25. Maercker, A., Schutzwohl, M., \& Zahava, S. (1999). Post-traumatic stress disorder: A lifespandevelopmental perspective. Seattle \&Toronto: Hogrefe \& Huber.

26. Maldonado, D.J (1975). Ethnic self-identity and self-understanding. Social Casework, 56, 618-622.

27. Mukangendo, M. C. (2007). Caring for children born of rape in Rwanda. In R. C. Carpenter (Ed.), Born of war: Protecting children of sexual violence survivors in conflict zones (pp.40-52). Bloomfield, CT: Kumarian Press.

28. National Institute for Health and Welfare (2015). School Health Survey: Friendship supports the well-being of young people. https://thl.fi/fi/-/kouluterveyskysely-ystavyyssuhteet-tukevat-nuorten-hyvinvointia.

29. Nordanger, Dag Ø. (2007) Coping with Loss and Bereavement in Post-war Tigray, Ethiopia. Transcultural Psychiatry, 44, 545-565.

30. Pearlin, L. I. (1993). The social context of stress. In L. Golberger \& S. Breznitz (2 ${ }^{\text {nd }}$ Eds.). Handbook of stress: Theoretical and clinical aspects (pp. 303-315). New York: The free Press.

31. Phinney, J. (1990). Ethnic identity in adolescents and adults: Review of research. Psychological Bulletin, 180, 499-514. 
32. Phinney, J. S. \& Ong, A. D. (2007). Conceptualization and measurement of ethnic identity: Curent status and future directions. Journal of Counseling Psychology, 54, 271-281.

33. Phinney, J. S. (1992). The multigroup ethnic identity measure: a new scale for use with diverse groups. Journal of Adolescent Research, 7, 156-176.

34. Phinney, J., Horenczyk, G., Liebkind, K., \& Vedder, P. (2001). Ethnic identity, immigration, and well-being: An interpersonal perspective. Journal of Social Issues, 57, 493-510.

35. Rönkä, A. R. , Sunnari, V., Rautio A., Koiranen M., Taanila A (2017). Associations between school liking, loneliness and social relations among adolescents: Northern Finland Birth Cohort 1986 study. International Journal of Adolescence and Youth, 22, pp.93-106.

36. Rwomire, A. (2001). Social problems in Africa: New Visions. Westport, Connecticut: Prager Publishers.

37. Samovar, L. A., Porter, R. E., McDaniel, E. R., \& Roy, C. S. (2012). Communication between cultures. ( $8^{\text {th }}$ Ed.) Boston: Wardsworth.

38. Scheier, M. F., Carver, C. S. (1992). Effects of optimism on Psychological and physical well-being: Theoretical overview and empirical update. Cognitive Therapy and Research, 16, 201-228.

39. Schildt, J. (2013). The "here and there" of Rwandan reconciliation: Individual actors take centre stage. Louvain, Belgium: University Press.

40. Statistics Finland (2017). Suicides: Number of suicides 1921-201\%. https://findikaattori.fi/en/10\#_ga= 2.133864782.1377872187.15451279861606442452.1544439470

41. Statistics Finland (2018). Country of birth according to age and sex by region 1990-2018. http://pxnet2.stat.fi/PXWeb/pxweb/en/StatFin/StatFin__vrm_vaerak/statfin_vaerak_pxt_11rp.px/table/ tableViewLayout1/

42. Steele, C. M., \& Aronson, J. (1995). Stereotype vulnerability and the Intellectual test performance of AfricanAmericans. Journal of Personality and Social Psychology, 69, 797-811.

43. Suinn, R, M. (2010). Reviewing acculturation and Asian Americans: How acculturation affects health, adjustment, school achievement, and counseling. Asian American Journal of Psychology, 1, 5-17.

44. Van Ee, E., Kleber R. J, \& Mooren, G. T. (2012). War trauma lingers on... Associations between maternal PTSD, parent-child interaction and child development. Infant Mental Health Journal 33, 459-468

45. Verkuyten, M. (2006). The social psychology of ethnic identity: European Monographs in social Psychology. New York, NY: Psychology Press.

46. Wakefield, W. D. \& Hudley, C. (2009). Ethnic and racial identity and adolescent well-being. Adolescent mental health, 46, 147-154.

47. Weiss, R. S. (1973). Loneliness: The experience of emotional and social isolation. Cambridge, MA: MIT Press.

48. Weitz, R. (1990). Living with the stigm of AIDS. Qualitative Sociology, 13, 23-38.

49. World Health Organization (2016). Adolescent and mental health: News. https://www.who.int/en/news-room/ fact-sheets/detail/suicide

50. World Health Organization. (2016). World health statistics 2016: monitoring health for the SDGs sustainable development goals. World Health Organization.

51. World health organization. 2018. Adolescent mental health: News. http://www.who.int/news-room/fact-sheets/ detail/adolescent-mental-health

52. World Medical Association Declaration of Helsinki (2013). Ethical principles for medical research involving human subjects. JAMA, 310, 2191-2194.

53. Young, J. E. (1982). Loneliness, Depression and Cognitive Therapy: Theory and Application. In L. A. Peplau, \& D. Perlman (Eds.), Loneliness: A sourcebook of current theory, research and therapy (pp. 1-18). New York: Wiley. 